\title{
SYNTHESIS AND STRUCTURE OF COBALT(II) COMPLEX WITH 2,6-DIACETYLPYRIDINE-BIS(PHENYLHYDRAZONE)
}

\author{
SVETLANA BELOŠEVIĆ ${ }^{1}$, MARKO RODIĆ ${ }^{* *}$ MIRJANA RADANOVIĆ ${ }^{2}$, VUKADIN \\ LEOVAC ${ }^{2}$
}

${ }^{1}$ Faculty of Technical Sciences, University of Priština, Kosovska Mitrovica, Serbia

${ }^{2}$ Faculty of Sciences, University of Novi Sad, Novi Sad, Serbia

\begin{abstract}
The molecular and crystal structure of a newly synthesized Co(II) complex with 2,6-diacetylpyridine bis(phenylhydrazone) $(\mathrm{L})$, of the formula $\left[\mathrm{CoL}_{2}\right] \mathrm{I}_{2}$ are described. The reaction of warm EtOH solutions of the ligand, 2,6-diacetylpyridine bis(phenylhydrazone) and CoI 2 in molar ratio 1:1 resulted in formation of black single crystals of the title complex. This is the first and so far, the only metal complex with this ligand that is characterized by single crystal X-ray crystallography. Co(II) is situated in a distorted mer-octahedral surrounding of two tridentate $\mathrm{N}_{3}$ coordinated ligand molecules. Complex crystallizes in monoclinic crystal system in $C 2 / c$ space group. Besides X-ray analysis, conductometric, spectroscopic and magnetic properties of the complex are investigated.
\end{abstract}

Keywords: Metal complex, Hydrazone, 2,6-diacetylpyridine derivative, Structure determination.

\section{INTRODUCTION}

Hydrazones represent a large and versatile group of organic compounds, characterized by $>\mathrm{C}=\mathrm{N}-\mathrm{N}>$ atomic triade. They are usually prepared by the condensation of carbonyl compounds and hydrazine or its derivatives. Considering the variety of both carbonyl compounds and hydrazine derivatives, the large number of synthesized hydrazones is not surprising. This topic is very interesting for researchers, thus numerous review papers and monographs are published ( Guimarães et al., 2017; Kitaev, 1977; Kitaev \& Buzykin, 1974; Rollas et al., 2007; Shakdofa et al., 2014; Watanabe et al., 2018; Yang et al., 2016).

These compounds are important not only from theoretical, but also practical point of view (wide range of biological activity, catalytic activity, use as analytical reagents, etc.) (Guimarães et al., 2017; Rollas et al., 2007; Shakdofa et al., 2014; Watanabe et al., 2018; Yang et al., 2016).

Having different electron-donor atoms $(\mathrm{N}, \mathrm{O}, \mathrm{S}$, etc.) to coordinate the metal ions, made this group of compounds very interesting topic for coordination chemists (Kogan et al., 1990; Shakdofa et al., 2014; Watanabe et al., 2018). Among these ligands, 2,6-diacetylpyridine bis(hydrazones) stand out. These ligands can have different denticity, depending on the hydrazine derivative, but the most common are tri- and pentadentate ones.

The simplest ligand of this group is 2,6-diacetylpyridine bis(hydrazone), which is obtained in the reaction of hydrazine hydate and 2,6-diacetylpyridine (Shee et al., 2013). This $\mathrm{N}_{3}$ tridentate ligand coordinates the metal ion through pyridine and two imine nitrogen atoms, forming two 5-membered metallocycles. The only exception is a dimeric complex of $\mathrm{Cd}(\mathrm{II})$

\footnotetext{
* Corresponding author: marko.rodic@dh.uns.ac.rs
} CHEMISTRY in which, besides the mentioned three ligators, the terminal nitrogen atom is involved in coordination as a bridge (Shee et al., 2013).

In (Curry et al., 1967) synthesis, spectroscopic and magnetic characterization of mono- and bis(ligand) complexes of $\mathrm{Fe}(\mathrm{II}), \mathrm{Co}(\mathrm{II}), \mathrm{Ni}(\mathrm{II})$ and $\mathrm{Cu}(\mathrm{II})$ with 2,6-diacetylpyridine bis(phenylhydrazone) (L), of the general formulas $\mathrm{M}(\mathrm{L}) \mathrm{Cl}_{2}$, and $\left[\mathrm{ML}_{2}\right]\left(\mathrm{ClO}_{4}\right)_{2}$, are described.

The survey of the Cambridge Structural Database (version 5.39, update May 2018) (Groom et al., 2016) revealed that there are no structurally characterized metal complexes with this ligand. Here we report molecular and crystal structure, as well as some physicochemical properties of a novel complex of $\mathrm{CoI}_{2}$ with 2,6-diacetylpyridine bis(phenylhydrazone), of the formula $\left[\mathrm{CoL}_{2}\right] \mathrm{I}_{2}$. This is the first complex of any metal with this ligand, which is obtained in the form of single crystals, thus fully structurally characterized.

\section{EXPERIMENTAL}

\section{Materials and methods}

All chemicals used were commercial products of analytical reagent grade. Elemental analyses $(\mathrm{C}, \mathrm{H}, \mathrm{N})$ of air-dried complexes were carried out by standard micromethods in the Center for Instrumental Analyses, ICTM in Belgrade. Molar conductivities of freshly prepared complexes solutions $\left(c=1 \times 10^{-3} \mathrm{~mol} \mathrm{dm}^{-3}\right)$ were measured on a Jenway 4010 conductivity meter. IR spectra were recorded using $\mathrm{KBr}$ pellets on a NEXUS 670 FTIR spectrophotometer (Thermo Nicolet) in the range of $4000-400 \mathrm{~cm}^{-1}$. Melting points were measured on a Nagema melting point microscope Rapido. Magnetic susceptibility measurements were conducted at room temperature 
on an MSB-MKI magnetic susceptibility balance, Sherwood Scientific Ltd. Cambridge.

\section{Synthesis of ligand}

The mixture of $0.80 \mathrm{~g}$ (5 mmol) 2,6-diacetylpyridine and $1.45 \mathrm{~g}(10 \mathrm{mmol})$ phenylhydrazine-hydrochloride was heated in $10 \mathrm{~cm}^{3} \mathrm{EtOH}$. In the resulting red solution $2.00 \mathrm{~g}(20 \mathrm{mmol})$ LiOAc $\cdot 2 \mathrm{H}_{2} \mathrm{O}$ was added and this mixture was refluxed for 40 minutes, during which the solution became yellow. Cooling to the room temperature resulted in the formation of yellowish fibrous product, which was filtered and washed with $\mathrm{EtOH}$ and $\mathrm{Et}_{2} \mathrm{O}$. Yield: $1.28 \mathrm{~g}(75 \%)$. Anal. Calcd. for $\mathrm{C}_{21} \mathrm{H}_{21} \mathrm{~N}_{5}$ : C, 73.44; H, 6.16; N, 20.39. Found: C, 73.54; H, 6.05; N, 20.18. IR bands $\left[\tilde{\boldsymbol{\nu}} / \mathrm{cm}^{-1}\right.$ ]: $3432 \mathrm{~m}, 3347 \mathrm{~m}, 1601 \mathrm{vs}, 1563 \mathrm{~s}, 1508 \mathrm{~m}, 1452 \mathrm{~s}$, $1363 \mathrm{w}, 1291 \mathrm{w}, 1250 \mathrm{vs}, 1164 \mathrm{vs}, 1081 \mathrm{w}, 994 \mathrm{w}, 840 \mathrm{w}, 815 \mathrm{w}$, $750 \mathrm{~m}, 694 \mathrm{~m}, 650 \mathrm{w}, 507 \mathrm{w}$. M.p. $=216-218^{\circ} \mathrm{C}$.

\section{Synthesis of complex}

The mixture of $0.032 \mathrm{~g} \mathrm{CoI}_{2}(0.1 \mathrm{mmol})$ and $0.034 \mathrm{~g}(0.1$ mmol) of $\mathrm{L}$ was heated in $10 \mathrm{~cm}^{3}$ of $\mathrm{MeOH}$ until complete dissolution. The obtained dark solution was left at the room temperature and after two days black prismatic single crystals were filtered and washed with $\mathrm{MeOH}$. Yield: $0.030 \mathrm{~g}(60 \%)$. Anal. Calcd. for $\left[\mathrm{C}_{42} \mathrm{H}_{42} \mathrm{CoN}_{10}\right] \mathrm{I}_{2}: \mathrm{C}, 50.87 ; \mathrm{H}, 4.11 ; \mathrm{N}, 14.32$. Found: C, 50.46; H, 4.23; N, 14.01. IR bands [ $\tilde{\boldsymbol{v}} / \mathrm{cm}^{-1}$ ]: $3545 \mathrm{~m}$, $3410 \mathrm{~m}, 3160 \mathrm{~s}, 3097 \mathrm{~m}, 3050 \mathrm{~m}, 2980 \mathrm{~m}, 2938 \mathrm{~m}, 1598 \mathrm{vs}, 1515 \mathrm{~s}$, $1494 \mathrm{~s}, 1439 \mathrm{~m}, 1380 \mathrm{w}, 1261 \mathrm{vs}, 1170 \mathrm{~m}, 1090 \mathrm{~m}, 1049 \mathrm{~m}, 881 \mathrm{w}$, 804w, 750s, 694s, 662w, 501w. M.p. > $250{ }^{\circ} \mathrm{C}$. Molar conductivity, $\Lambda_{\mathrm{M}}\left(\mathrm{S} \mathrm{cm}^{2} \mathrm{~mol}^{-1}\right): 150(\mathrm{MeOH}) . \mu_{\mathrm{eff}}(\mathrm{BM}): 4.58$.

\section{Crystal structure determination}

Diffraction experiment was performed on an Oxford Diffraction Gemini S diffractometer, equipped with Sapphire3 detector. The measurements were performed at room temperature. Radiation from sealed tube with Mo-anode was used. Unit cell determination, data collection, and reduction was performed with the CrysAlisPro software ( Rigaku Corporation, 2015). The crystal structure was solved by using SHELXT (Sheldrick, 2015a), and refined by full-matrix least squares method by using SHELXL-2018 (Sheldrick, 2015b) and ShelXle (Hübschle et al., 2011). Software used for crystal structure analysis: PLATON (Spek, 2009), Mercury CSD (Macrae et al., 2008), and CrystalExplorer (Turner et al., 2017).

CCDC 1883840 contains the supplementary crystallographic data for this paper. These data can be obtained free of charge from The Cambridge Crystallographic Data Centre via www.ccdc.cam.ac.uk/structures.

A summary of the crystallographic data for crystal structures is given in Table 1 .
Table 1. Crystallographic data and refinement statistics.

\begin{tabular}{|c|c|}
\hline \multicolumn{2}{|l|}{ Crystal data } \\
\hline Chemical formula & {$\left[\mathrm{C}_{42} \mathrm{H}_{42} \mathrm{CoN}_{10}\right] \mathrm{I}_{2}$} \\
\hline$M_{\mathrm{r}}\left(\mathrm{g} \mathrm{cm}^{-3}\right)$ & 999.58 \\
\hline Crystal system & Monoclinic \\
\hline Space group & $C 2 / c$ \\
\hline Temperature $(\mathrm{K})$ & 294 \\
\hline$a(\AA)$ & $21.1576(4)$ \\
\hline$b(\AA)$ & $15.8949(3)$ \\
\hline$c(\AA)$ & $12.1287(2)$ \\
\hline$\beta\left(^{\circ}\right)$ & $92.247(2)$ \\
\hline$V\left(\AA^{3}\right)$ & $4075.72(13)$ \\
\hline$Z$ & 4 \\
\hline Crystal size $(\mathrm{mm})$ & $0.69 \times 0.42 \times 0.27$ \\
\hline \multicolumn{2}{|l|}{ Data collection } \\
\hline Diffractometer & $\begin{array}{l}\text { Gemini S (Oxford } \\
\text { Diffraction) }\end{array}$ \\
\hline Radiation type & Мо $K \alpha$ \\
\hline No. of measured reflections & 17919 \\
\hline No. of independent reflections & 4839 \\
\hline $\begin{array}{l}\text { No. of observed }[I>2 \sigma(I)] \\
\text { reflections }\end{array}$ & 4092 \\
\hline$R_{\text {int }}$ & 0.020 \\
\hline$(\sin \theta / \lambda)_{\max }\left(\AA^{-1}\right)$ & 0.678 \\
\hline$\mu\left(\mathrm{mm}^{-1}\right)$ & 1.98 \\
\hline Absorption correction & Analytical \\
\hline$T_{\min }, T_{\max }$ & $0.168,0.467$ \\
\hline \multicolumn{2}{|l|}{ Refinement } \\
\hline No. of reflections & 4839 \\
\hline No. of parameters & 257 \\
\hline No. of restraints & 2 \\
\hline H-atom treatment & Mixed \\
\hline$R\left[F^{2}>2 \sigma\left(F^{2}\right)\right]$ & 0.032 \\
\hline$w R\left(F^{2}\right)$ & 0.079 \\
\hline$S$ & 1.05 \\
\hline$\Delta \rho_{\max }, \Delta \rho_{\min }\left(\mathrm{e} \AA^{-3}\right)$ & $0.74,-0.71$ \\
\hline
\end{tabular}

\section{RESULTS AND DISCUSSION}

Synthesis and physicochemical characterization of the compounds

Ligand, 2,6-diacetylpyridine bis(phenylhydrazone) is obtained in a good yield (75\%) in the reaction of warm $\mathrm{EtOH}$ solutions of stochiometric amounts of 2,6-diacetylpyridine and phenylhydrazine hydrochloride in the presence of the excess of LiOAc (scheme 1).

It should be mentioned that the same ligand was earlier obtained in the reaction of warm EtOH solutions of 2,6diacetylpyridine and neutral phenylhydrazine (Curry et al., 1967).

The ligand is well soluble in acetone, partially soluble in $\mathrm{MeOH}$ and $\mathrm{EtOH}$, and insoluble in $\mathrm{Et}_{2} \mathrm{O}$ and $\mathrm{H}_{2} \mathrm{O}$. Hydrazone structure of the ligand, i.e. the condensation of both of ketogroups of the diketone, could be proven by the elemental 
analysis, but also the absence of the characteristic very strong carbonyl band at $1707 \mathrm{~cm}^{-1}$ in the IR spectrum of the ligand.<smiles>CC(=O)c1cccc(C(C)=O)n1</smiles>

Scheme 1. Synthesis of the ligand.

Black single crystals of the complex are obtained in a good yield $(60 \%)$ in the reaction of warm $\mathrm{EtOH}$ solutions of the ligand and $\mathrm{CoI}_{2}$. Despite the fact that metal-ligand molar ratio was $1: 1$, bis(ligand) complex was formed. Unlike this bis(ligand) complex, in (Curry et al., 1967) the synthesis of mono(ligand) complex of the formula $\mathrm{Co}(\mathrm{L}) \mathrm{Cl}_{2}$ is reported. The obtained complex is stable in air and high temperatures (M.p. $>250{ }^{\circ} \mathrm{C}$ ), partially soluble in $\mathrm{EtOH}$ and $\mathrm{H}_{2} \mathrm{O}$, while its solubility in $\mathrm{MeOH}$ and DMF is better. Molar conductivity of $\mathrm{MeOH}$ solution of the complex has a value characteristic for 2:1 electrolyte type, thus is in concordance with the coordination formula (Geary, 1971). The value of the effective magnetic moment $\left(\mu_{\mathrm{eff}}=4.58 \mathrm{BM}\right)$ is characteristic for high-spin octahedral Co(II) complexes.

In the IR spectrum of the complex, the band at $3155 \mathrm{~cm}^{-1}$ could be ascribed to $v(\mathrm{NH})$ vibrations. Other high-energy bands $\left(3100-2940 \mathrm{~cm}^{-1}\right)$ correspond to the $v(\mathrm{CH})$ vibrations of $\mathrm{CH}_{3}-$ groups and aromatic rings (pyridine and benzene). Bands at 1599 and $1494 \mathrm{~cm}^{-1}$ could be assigned to $v(\mathrm{C}=\mathrm{C})$ and $v(\mathrm{C}-\mathrm{N})$ vibrations of pyridine and benzene rings, while the band at 1517 $\mathrm{cm}^{-1}$ corresponds to $v(\mathrm{C}=\mathrm{N})$ vibrations of imine group. In free ligand, the latter is found at higher energy $\left(1563 \mathrm{~cm}^{-1}\right)$, and due to coordination of nitrogen atom suffers a negative shift (Curry et al., 1967; Kazak et al., 2009).

\section{Crystal structure of the complex}

The compound crystallizes in monoclinic crystal system, space group $C 2 / c$. The content of the asymmetric unit, atom numeration, and molecular structure are depicted in Fig. 1. The complex cation exhibits a perfect $C_{2}$ symmetry imposed by the space-group symmetry since $\mathrm{Co}$ (II) atom occupies a special position. Thus, the asymmetric unit of the unit cell is comprised of a ligand molecule, half of a metal atom, and an iodide ion. The search for higher non-crystallographic symmetry of the complex cation by the method of Continuous Symmetry Measures (Zabrodsky et al., 1992) indicates that cation symmetry only slightly deviates from $D_{2}$ point group, as $\operatorname{CSM}\left(D_{2}\right)=0.251$. Apart from the crystallographic two-fold axis, the two additional noncrystallographic two-fold axes are positioned along N1-Co1-N1 bonds and the bisector of $\mathrm{N} 2 \mathrm{~A}-\mathrm{N} 2 \mathrm{~B}^{\mathrm{i}}$ angle [symmetry code (i): $-x+1, y,-z+1 / 2]$.

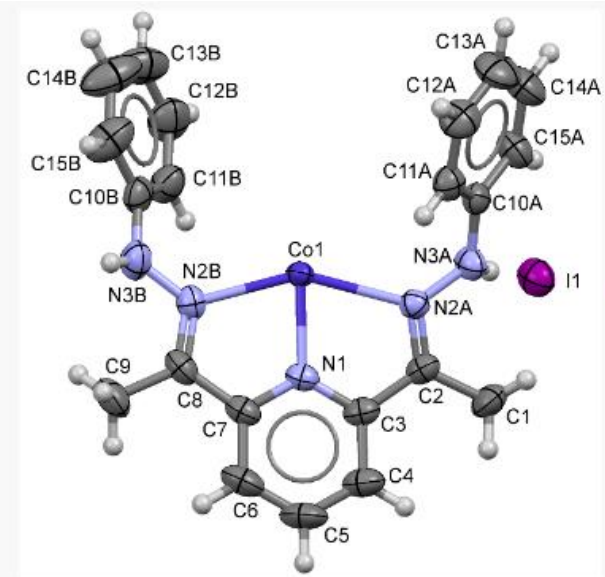

a)

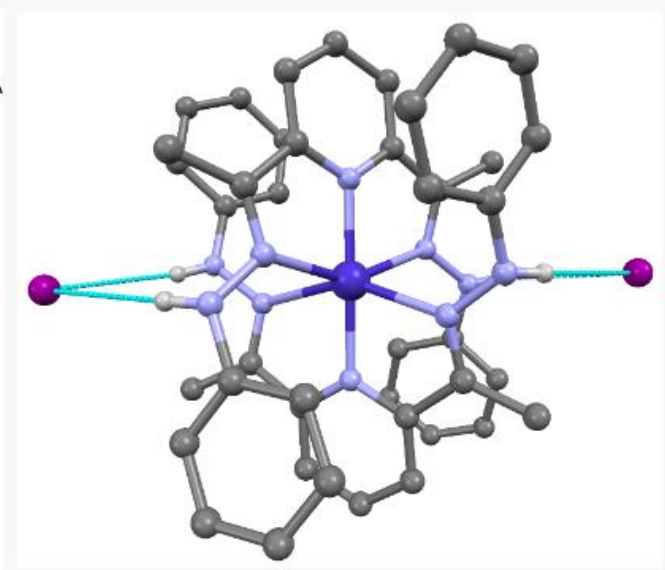

b)

Figure 1. a) Asymmetric unit of $\left[\mathrm{CoL}_{2}\right] \mathrm{I}_{2}$ and atom labeling scheme. Displacement ellipsoids are drawn at the $50 \%$ probability level. Hydrogen atoms have been drawn as spheres of arbitrary radius. b) Perspective view of the molecular structure of [CoL $\mathrm{C}_{2}$.

The $\mathrm{Co}(\mathrm{II})$ atom is situated in a distorted octahedral environment, formed by two meridionally arranged tridentate $\mathrm{N}_{3}$ chelate ligands. The octahedra is distorted, as two ligands are not mutually perpendicular. The planes defined by N1, N2A and $\mathrm{N} 2 \mathrm{~B}$ donor atoms of the symmetry-related ligands enclose the dihedral angle of $75.65(6)^{\circ}$. The valence angles within the 
coordination polyhedron deviate from ideal values (Table 2). The trans-valence angle $\mathrm{N} 2 \mathrm{~A}-\mathrm{Co} 1-\mathrm{N} 2 \mathrm{~A}$ and cis-valence angles N1Co1-N2A, N1-Co1-N2B with values of $150.69(7)^{\circ}, 74.14(7)^{\circ}$, and $76.56(8)^{\circ}$, respectively, display the largest deviations. This is caused by geometry constraints imposed by the ligand structure and its chelate coordination.

Table 2. Selected bond lengths $(\AA)$, valence and torsion angles $\left({ }^{\circ}\right)$.

\begin{tabular}{|l|l|l|l|}
\hline Bonds & Length $(\AA)$ & Bonds & Angle $\left(^{\circ}\right)$ \\
\hline Co1-N1 & $2.0061(18)$ & N1-Co1-N1 & $173.87(11)$ \\
Co1-N2B & $2.1993(19)$ & N2A-Co1-N2B & $150.69(7)$ \\
Co1-N2A & $2.3057(19)$ & N1-Co1-N2A & $74.14(7)$ \\
N1-C3 & $1.338(3)$ & N1-Co1-N2B & $76.56(8)$ \\
N1-C7 & $1.346(3)$ & & \\
C2-C3 & $1.467(3)$ & Bonds & Torsion angle $\left(^{\circ}\right)$ \\
C7-C8 & $1.465(4)$ & N1-C3-C2-N2A & $16.1(3)$ \\
N2A-C2 & $1.298(3)$ & C2-N2A-N3A-C10A & $4.3(3)$ \\
N2B-C8 & $1.302(3)$ & C8-N2B-N3B-C10B & $-161.1(2)$ \\
N2A-N3A & $1.374(3)$ & & $-165.6(2)$ \\
N2B-N3B & $1.366(3)$ & & \\
N3A-C10A & $1.390(3)$ & & \\
N3B-C10B & $1.400(4)$ & & \\
\hline
\end{tabular}

Symmetry code: (i) $-x+1, y,-z+1 / 2$;

The two five-membered chelate rings are not planar and their conformational analysis is problematic due to large discrepancy between ring bond lengths. The method of Duax et al. (1976) reveals that conformations of these rings are intermediate between the envelope $(E)$ and half-chair $(T)$ forms. For the Co1-N1-C3-C2-N2A metallocycle, the lowest values of $\Delta C_{\mathrm{s}}$ asymmetry parameters are $\Delta C_{\mathrm{s}}(\mathrm{Co} 1-\mathrm{N} 1)=\Delta C_{\mathrm{s}}(\mathrm{C} 2)=6.9(2)^{\circ}$ and $\Delta C_{\mathrm{s}}(\mathrm{N} 1-\mathrm{C} 3)=\Delta C_{\mathrm{s}}(\mathrm{N} 2 \mathrm{~A})=9.1(2)^{\circ}$, which point to ${ }^{4} E$ and $E_{5}$ conformations, respectively. Also, the lowest $\Delta C_{2}$ asymmetry parameter is $\Delta C_{2}(\mathrm{C} 2-\mathrm{N} 2 \mathrm{~A})=\Delta C_{2}(\mathrm{~N} 1)=2.3(2)^{\circ}$, which suggests ${ }^{4} T_{5}$ conformation. Similarly, for the Co1-N1-C7-C8-N2B ring, the lowest $\Delta C_{\mathrm{s}}$ asymmetry parameters $\Delta C_{\mathrm{s}}(\mathrm{C} 7-\mathrm{C} 8)=\Delta C_{\mathrm{s}}(\mathrm{Co} 1)=$ $3.9(3)^{\circ}$ and $\Delta C_{\mathrm{s}}(\mathrm{N} 1-\mathrm{C} 7)=\Delta C_{\mathrm{s}}(\mathrm{N} 2 \mathrm{~B})=4.6(2)^{\circ}$ hint to ${ }^{1} E$ and $E_{5}$ conformations, respectively. Again, the lowest $\Delta C_{2}$ asymmetry parameter is $\Delta C_{2}(\mathrm{~N} 2 \mathrm{~B}-\mathrm{Co} 1)=\Delta C_{2}(\mathrm{C} 7)=2.3(2)^{\circ}$ which signals ${ }^{1} T_{5}$ conformation.

To resolve this ambiguity, a different approach by the method of Cremer \& Pople (1975), followed by decomposition of puckering parameters into linear combinations of two basic forms ( $E$ and $T$ ) by the method of Evans \& Boeyens (1989) was applied. The results are summarized in Table 3 . The findings confirm that conformations of both rings are best described as a mixture of half-chair and envelope forms. For the ring Co1-N1C3-C2-N2A, the conformation is described as $63 \% E_{5}$ and $37 \%$ ${ }^{4} T_{5}$, while the conformation of ring Co1-N1-C7-C8-N2B is expressed as $57 \%{ }^{1} T_{5}$ and $43 \% E_{5}$.

Table 3. Cremer-Pople puckering parameters of five-membered rings.

\begin{tabular}{|l|l|l|l|}
\hline Ring & $Q_{2} / \AA$ & $\varphi_{2} /{ }^{\circ}$ & $a \varphi(E)+b \varphi(T)^{*}$ \\
\hline Co1-N1-C3-C2-N2A & $0.169(2)$ & $317.3(7)$ & $62.7(1.8)+37.3(1.7)$ \\
\hline Co1-N1-C7-C8-N2B & $0.1632(18)$ & $349.7(9)$ & $42.8(2.0)+57.2(1.9)$ \\
\hline
\end{tabular}

* $a$ and $b$ are given as percentages. $\varphi$ is expressed as a multiple of $\pi / 2 N$.

The ligand is coordinated in a neutral form through nitrogen atoms of the pyridine ring, and two azomethine nitrogen atoms. The same coordination mode is found in $\left[\mathrm{ZnL}_{2}\right]\left(\mathrm{CF}_{3} \mathrm{O}_{3} \mathrm{~S}\right)_{2}$, where $\mathrm{L}$ is structurally related ligand 2,6-diformylpyridine bis(phenylhydrazone) (Dumitru et al., 2009). Metal-ligand bond lengths are in the range of 2.0061(18)-2.3057(19) $\AA$, with Co$\mathrm{N} 1$ being the shortest one. The two phenylhydrazine moieties are asymmetrically coordinated, as indicated by different metalligand bond lengths (Table 2). Intra-ligand bond lengths are in the expected range. The bonds within pyridine and both phenyl rings have lengths indicative of electron delocalization along these moieties. The bonds $\mathrm{C} 2-\mathrm{N} 2 \mathrm{~A}$ and $\mathrm{C} 8-\mathrm{N} 2 \mathrm{~B}$ are the only two that have lengths characteristic of localized double bonds.
The ligand molecule significantly deviates from planarity. In order to avoid steric clashes with symmetry-related ligand within the coordination polyhedron, a twisting of phenylhydrazine moieties occurs. The magnitude or twisting along $\mathrm{C} 3-\mathrm{C} 2$ bond is greater when compared with that along $\mathrm{C} 7-\mathrm{C} 8$ bond, visualized through the values of torsion angles $\tau(\mathrm{N} 1-\mathrm{C} 3-\mathrm{C} 2-\mathrm{N} 2 \mathrm{~A})=16.1(3)^{\circ}$ and $\tau(\mathrm{N} 1-\mathrm{C} 7-\mathrm{C} 8-\mathrm{N} 2 \mathrm{~B})=4.3(3)^{\circ}$. The torsion along N2A-N3A and N2B-N3B bonds is similar in magnitude, yet in opposite sense relative to the chelate plane $\left[\tau(\mathrm{C} 2-\mathrm{N} 2 \mathrm{~A}-\mathrm{N} 3 \mathrm{~A}-\mathrm{C} 10 \mathrm{~A})=-161.1(2)^{\circ}\right.$, and $\tau(\mathrm{C} 8-\mathrm{N} 2 \mathrm{~B}-\mathrm{N} 3 \mathrm{~B}-$ $\left.\mathrm{C} 10 \mathrm{~B})=-165.6(2)^{\circ}\right]$. The mentioned differences between twisting along these bonds lead to significant differences in the final positions of phenyl rings $\mathrm{A}$ and $\mathrm{B}$ with the respect to the position of the pyridine ring of the symmetry-related ligand 
belonging to the same coordination sphere, as it is tabulated in Table 2.

The packing of structural units is dominated by the large complex cation. Cation's Hirshfeld surface (HS) decomposition into intermolecular atom-atom contacts (Fig. 2), reveals that $68.4 \%$ of the HS is dominated by cation-cation $\mathrm{H} \cdots \mathrm{H}$ contacts at distances around or beyond the sum of their Van der Waals radii.
The $\mathrm{C} \cdots \mathrm{H}$ and $\mathrm{H} \cdots \mathrm{C}$ contacts comprise $13.2 \%$ of the cation's HS. Due to the large discrepancy between cation and anion sizes, only $13.6 \%$ of the cation $\mathrm{HS}$ can be ascribed to the $\mathrm{H} \cdots \mathrm{I}$ contacts. However, these contacts correspond to the regions with

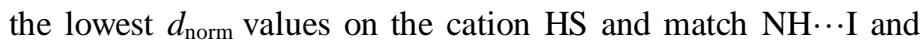
CH...I hydrogen bonds (Table 4). The anion's HS is over $99 \%$ mapped with $\mathrm{I} \cdot \mathrm{H}$ contacts.
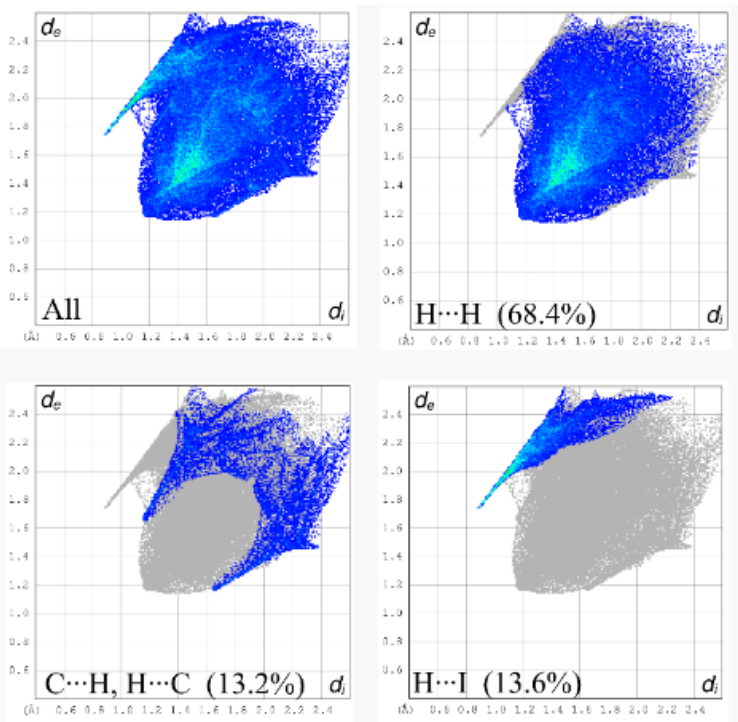

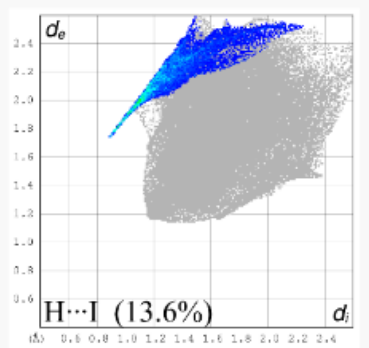

a)

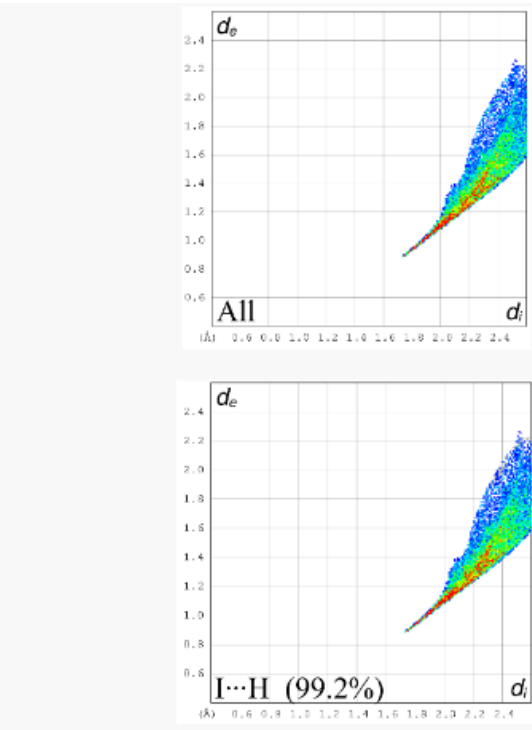

b)

Figure 2. Fingerprint plot of intermolecular contacts, and its decomposition based on specific atom-atom contacts for cation $\left[\mathrm{CoL}_{2}\right]^{2+}$ (a) and anion $\mathrm{I}^{-}(\mathrm{b})$.

Table 4. Selected hydrogen-bond parameters.

\begin{tabular}{|l|l|l|l|l|}
\hline$D-\mathrm{H} \cdots A$ & $D-\mathrm{H}(\AA)$ & $\mathrm{H} \cdots A(\AA)$ & $D \cdots A(\AA)$ & $D-\mathrm{H} \cdots A\left({ }^{\circ}\right)$ \\
\hline N3A-H3A $\cdots \mathrm{I} 1$ & $0.842(17)$ & $2.802(18)$ & $3.633(2)$ & $170(3)$ \\
\hline N3B-H3B $\cdots \mathrm{I} 1^{\text {i }}$ & $0.842(17)$ & $2.87(2)$ & $3.690(2)$ & $166(3)$ \\
\hline $\mathrm{C} 1-\mathrm{H} 1 \mathrm{C} \cdots \mathrm{I} 1$ & 0.96 & 3.16 & $3.947(3)$ & 140.3 \\
\hline $\mathrm{C} 6-\mathrm{H} 6 \cdots \mathrm{I} 1^{\text {ii }}$ & 0.93 & 3.06 & $3.944(3)$ & 158.9 \\
\hline $\mathrm{C} 9-\mathrm{H} 9 \mathrm{C} \cdots \mathrm{I} 1^{\text {i }}$ & 0.96 & 3.18 & $3.927(3)$ & 136.1 \\
\hline
\end{tabular}

Symmetry code(s): (i) $-x+1, y,-z+1 / 2$; (ii) $x-1 / 2,-y+1 / 2, z-1 / 2$.

\section{CONCLUSION}

By the reaction of warm methanolic solutions of $\mathrm{CoI}_{2}$ and tridentate $\mathrm{N}_{3}$ 2,6-diacetylpyridine bis(phenylhydrazone), L, not only in molar ratio $1: 2$, but also in molar ratio $1: 1$, high-spin bis(ligand) complex of the formula $\left[\mathrm{CoL}_{2}\right] \mathrm{I}_{2}$ is obtained. Single crystal X-ray analysis has shown that the complex has a distorted mer-octahedral configuration. This is the first and so far, the only complex of any metal with the titled ligand, that is characterized by single crystal X-ray analysis.

\section{ACKNOWLEGMENTS}

This work was supported by the Ministry of Education and Science of the Republic of Serbia, grants OI172014 and III41010.

\section{REFERENCES}

Cremer, D., \& Pople, J. A. 1975. General definition of ring puckering coordinates. Journal of the American Chemical Society, 97(6), pp. 1354-1358. doi:10.1021/ja00839a011

Curry, J. D., Robinson, M. A., \& Busch, D. H. 1967. Metal complexes derived from substituted hydrazones of 2,6diacetylpyridine. Inorganic Chemistry, 6(8), pp. 1570-1574. doi:10.1021/ic50054a032

Duax, W. L., Weeks, C. M., \& Rohrer, D. C. 1976. Crystal Structures of Steroids. In N. L. Allinger \& E. L. Eliel Eds., Topics in Stereochemistry. Hoboken, NJ, USA: Wiley., pp. 271-383. doi:10.1002/9780470147184.ch5

Dumitru, F., Legrand, Y., Barboiu, M., Petit, E., \& Lee, A.v. 2009. Metallosupramolecular Architectures of Pseudoterpyridine-Type Ligands and Zn II Metal Ions. Crystal Growth and Design, 9(6), pp. 2917-2921. doi:10.1021/cg9002466 
Evans, D. G., \& Boeyens, J. C. A. 1989. Conformational analysis of ring pucker. Acta Crystallographica Section B Structural Science, 45(6), pp. 581-590. doi: $10.1107 / \mathrm{s} 0108768189008190$

Geary, W. J. 1971. The use of conductivity measurements in organic solvents for the characterisation of coordination compounds. Coordination Chemistry Reviews, 7(1), pp. 81122. doi:10.1016/s0010-8545(00)80009-0

Guimarães, G. D., Rolim, A. L., de Gonsalves, A. A., \& Araújo, M. C. R. 2017. Biological Potential of Synthetic Hydrazones in the Last Decade: A Systematic Review. Revista Virtual de Química, 9(6), pp. 2551-2592. doi:10.21577/19846835.20170151

Groom, C. R., Bruno, I. J., Lightfoot, M. P., \& Ward, S. C. 2016. The Cambridge Structural Database. Acta Crystallographica Section B Structural Science, Crystal Engineering and Materials, 72(2), pp. 171-179. doi:10.1107/s2052520616003954

Hübschle, C. B., Sheldrick, G. M., \& Dittrich, B. 2011. ShelXle: a Qt graphical user interface for SHELXL. Journal of Applied Crystallography, 44(6), pp. 1281-1284. doi: $10.1107 / \mathrm{s} 0021889811043202$

Kazak, C., Arslan, N. B., Karabulut, S., Azaz, A. D., Namlı, H., \& Kurtaran, R. 2009. Supramolecular lead(II) azide complex of 2,6-diacetylpyridine dihydrazone: synthesis, molecular structure, and biological activity. Journal of Coordination Chemistry, 62(18), pp. 2966-2973. doi:10.1080/00958970902980537

Kitaev, Y. P. 1977. Khimiya gidrazonov. Moscow: Nauka.

Kitaev, Y. P., \& Buzykin, B. I. 1974. Gidrazony. Moscow: Nauka.

Kogan, V. A., Zelentsov, V. V., Larin, G. M., \& Lukov, V. V. 1990. Kompleksy perekhodnykh metallov c gidrazomani. Moscow: Nauka.

Macrae, C. F., Bruno, I. J., Chisholm, J. A., Edgington, P. R., McCabe, P., Pidcock, E., Rodriguez-Monge, L., Taylor, R., van de Streek, J., Wood, P. A. 2008. Mercury CSD 2.0: New features for the visualization and investigation of crystal structures. Journal of Applied Crystallography, 41(2), pp. 466-470. doi:10.1107/s0021889807067908
-Rigaku Corporation. 2015. Rigaku Oxford Diffraction; CrysAlisPro Software system. Oxford, UK.

Rollas, S., \& Küçükgüzel, S. 2007. Biological Activities of Hydrazone Derivatives. Molecules, 12(8), pp. 1910-1939. doi:10.3390/12081910

Shakdofa, M. M. E., Shtaiwi, M. H., Morsy, N., \& Abdel-rassel, T. M. A. 2014. Metal complexes of hydrazones and their biological, analytical and catalytic applications: A review. Main Gr. Chem., 13, 187-218. https://doi.org/10.3233/MGC-140133.

Shee, N. K., Dutta, S., Drew, M. G. B., \& Datta, D. 2013. Bis complexes of zinc(II), cadmium(II) and mercury(II) with a potentially pentadentate $\mathrm{N}$-donor ligand. Lewis acidity versus coordination tendency. Inorganica Chimica Acta, 398, pp. 132-135. doi:10.1016/j.ica.2012.12.024

Sheldrick, G. M. 2015a. SHELXT - Integrated space-group and crystal-structure determination. Acta Crystallographica Section A Foundations and Advances, 71(1), pp. 3-8. doi:10.1107/s2053273314026370

Sheldrick, G. M. 2015b. Crystal structure refinement with SHELXL. Acta Crystallographica Section C Structural Chemistry, 71(1), pp. 3-8. doi:10.1107/s2053229614024218

Spek, A. L. 2009. Structure validation in chemical crystallography. Acta Crystallographica Section D Biological Crystallography, 65(2), pp. 148-155. doi:10.1107/s090744490804362x

Turner, M. J., Mckinnon, J. J., Wolff, S. K., Grimwood, D. J., Spackman, P. R., Jayatilaka, D., \& Spackman, M. A. 2017. CrystalExplorer.University of Western Australia. 17.

Watanabe, K., Mino, T., Yoshida, Y., \& Sakamoto, M. 2018. Hydrazone-Palladium Catalyzed Reactions Using Allyl Compounds. Journal of Synthetic Organic Chemistry, Japan, 76(8), pp. 828-837. doi:10.5059/yukigoseikyokaishi.76.828

Yang, Y., Gao, C., Liu, J., \& Dong, D. 2016. Recent developments in rhodamine salicylidene hydrazone chemosensors. Analytical Methods, 8(14), pp. 2863-2871. doi:10.1039/c6ay00135a

Zabrodsky, H., Peleg, S., \& Avnir, D. 1992. Continuous symmetry measures. Journal of the American Chemical Society, 114(20), pp. 7843-7851. doi:10.1021/ja00046a033 